\title{
Yesca y fuego. Condicionantes de la conducta sexual del servicio doméstico español en el siglo XVIII*
}

\author{
Daniel Santiago Baldellou Monclús \\ Universidad de Zaragoza \\ Francisco José Alfaro Pérez \\ Universidad de Zaragoza
}

RESUMEN: El presente artículo analiza a los empleados del servicio doméstico en el siglo XVIII y principios del XIX con el objetivo de conocer y determinar sus posiciones ante la necesidad de conservar su honra en un espacio extraño y, por otro lado, el imperativo social o biológico de buscar pareja y colocación. El servicio doméstico español del Antiguo Régimen, especialmente el femenino, estaba expuesto a multitud de riesgos, entre los que se hallaba muy presente el del sexo desde su versión más romántica a la más cruel. En este estudio analizamos algunas de las conductas más usuales a partir de documentación procesal de los siglos XVII y XVIII mediante el análisis de los conflictos reflejados en dichas fuentes. La precariedad de las criadas, los recursos legales que las amparaban, el uso que se hacía de ellos, la visión de la sociedad o las estrategias de los pretendientes son cuestiones tratadas en el texto con el fin de contextualizar de forma precisa los peligros del sexo y sus consecuencias. Los resultados reflejan un notable papel de la tradición y los tribunales como recursos femeninos para defender sus intereses y las estrategias de estas criadas en un ambiente hostil.

\section{PALABRAS CLAVE: Servicio doméstico; mujer; sexualidad; moral; ma- trimonio; justicia.}

* Este estudio se ha realizado en el marco de los proyectos de investigación HAR 201234576 del Ministerio de Economía y Competitividad y HAR2008-02392 del Ministerio de Ciencia e Innovación, dirigidos respectivamente por los profesores Encarna Jarque Martínez y José Antonio Salas Auséns. Abreviaturas: ADZ: Archivo Diocesano de Zaragoza; ADH: Archivo Diocesano de Huesca; ADB: Archivo Diocesano de Barbastro; ADP: Archivo Diocesano de Pamplona. 


\title{
Tinder and Fire. Determinants of Sexual Behaviour for Domestic Servants in XVIII
} Century Spain

\begin{abstract}
This article analyzes the position of domestic workers between the late seventeenth and early nineteenth centuries in order to determine what their situation facing the dilemma of preserving their honor in an, usually, hostile enviroment and the social imperative of courting and got married placed on them. The Spanish domestic service in the Old Regime Spain, specially the maids, was exposed to plenty of risks. Sexual harassement was by far one of the most common. This happening could appear in several forms, since an originally consented relationship until crimes such as raping. Through this paper, we annalyze the most common servant's sexual conducts based on the court documentation for the XVII and XVIII centuries by analyzing the conflicts reflected in these sources. Maids precariousness, their legal resources and the society perspective over their position are the issues adressed in the paper searching for a overview of the servant's sexual dangers and its consequences as well as the maid's strategies in openly hostile ambient.
\end{abstract}

KEY WORDS: Domestic labour; woman; sexuality; morality; marriage; justice.

«No por qué otros sean unos santos; si dijera otra cosa pecaría; pero conozco que es yesca la mujer; el hombre fuego; el enemigo, pajuela; la ocasión, el pedernal el eslabón, la flaqueza; la tentación da un chasquido y la resistencia vuela" 1

Como en estos versos, numerosos comediógrafos de los siglos XVII y XVIII — siguiendo una tradición literaria muy antigua - escribieron irónicas tonadillas, coplas, sainetes y otras composiciones musicales y teatrales alertando sobre los peligros de la tentación de la carne. Los literatos de la segunda mitad del siglo XVIII, sobre todo en las últimas décadas, protagonizaron un intento por dejar atrás aquel grave tono barroco con el que se trataban estos temas. La literatura que vinculaba al pecado carnal con las desgracias co-

1 GONZÁlez DEL CASTILlO, Juan Ignacio, Obras Completas, Tomo II, Madrid, R.A.E., 1914, 348. 
mo castigos divinos, pasó a tratar este tipo de debilidades con mayor ligereza y de manera más pragmática, incluso con cierta ironía ${ }^{2}$.

A pesar del registro menos dramático con el que algunos de estos autores dieciochescos hablaban del deseo sexual, el eje central de sus relatos continuaba siendo el mismo: un pecado, una vergüenza y un golpe a la reputación. La tardía e incompleta abrogación por parte de los tribunales de la corona hispánica de las jurisdicciones sobre familia, relaciones carnales y todos aquellos asuntos que podían identificarse más fácilmente con los pecados y las faltas religiosas, motivó situaciones muy diversas en sus distintos territorios, una fuente inagotable de agridulce inspiración para las plumas de los más avezados. Diferencias que emanaban no sólo de la cultura, la economía o la administración, sino también de los distintos marcos jurídicos en lo que se enmarcaban ${ }^{3}$.

Por encima de todo ello, a lo largo del siglo XVIII las ideas ilustradas fueron impregnando a las elites sociales de cada lugar, hasta despertar en ellas una creciente necesidad por regular los valores morales de la sociedad. El proceso de racionalización debía partir desde lo más básico, esto es: del individuo y su primera estructura pluripersonal, la familia ${ }^{4}$. En realidad, per se, no se trataba de algo nuevo; el punto de inflexión que introdujo el siglo XVIII fue un cambio en el discurso sobre el modelo social. La percepción heredada de los matrimonios y de las relaciones carnales como una representación de lo divino y lo pecaminoso dio paso a una visión del matrimonio y de la familia caracterizada por un código que pretendía obtener su control con el fin de modelar un estado de acuerdo con unos cánones ilustrados ${ }^{5}$.

Es por ello que, en el presente estudio, hemos considerado interesante centrarnos en el análisis de algunos problemas y transgresiones del orden pretendido, con el fin de conocer la respuesta dada a los mismos por aquella sociedad en ciernes. Concretamente, nos aproximaremos a través de los abusos o problemas derivados del sexo sufridos por el servicio doméstico femenino y lo haremos desde una doble perspectiva: la socio-legislativa, como no podía ser menos, y la cultural que nos permitirá destacar la importancia del lenguaje y de la literatura como elementos capaces de cambiar la percepción social de las criadas y de las relaciones prematrimoniales en general ${ }^{6}$.

2 La existencia de un género burlesco fue una constante en la literatura española, sin embargo el siglo XVIII vio un aumento de estos acercamientos jocosos a este tipo de situaciones que en la vida cotidiana desencadenaban auténticos dramas. CRESPO, 1979: 17-66.

3 GARCÍA GONZÁLEZ: 2008.

4 CHACÓN, 2011: 325-392.

5 CABRERA, 2001: 255-272.

6 Sobre esta cuestión véase, entre otros, BOLUFER, 1998. BELTRÁN TARRÉS, 2000: 55-79. 
Las fuentes utilizadas para rastrear este tipo de conflictos son fundamentalmente los procesos seguidos por los tribunales eclesiásticos en las diócesis aragonesas entre los años 1680 y 1820 . La extensión temporal de la muestra recogida nos permite hacernos una idea de la regularidad de este tipo de denuncias por esponsales incumplidos, por estupro u otras realizadas ante estas cortes, frecuentemente por mujeres que en un notable porcentaje ejercían de criadas. La muestra sobre la que se trabaja en el presente estudio está compuesta por un total de 474 pleitos por estupro o jactancia matrimonial de entre los cuales 83 casos, un $17,5 \%$ del total, estaban protagonizados por criadas que llevaron a pleito el incumplimiento de una promesa matrimonial por parte de un varón con el que consintieron tener trato carnal y del cual en no pocas ocasiones habían quedado embarazadas.

\section{LAS IMÁGENES DEL SERVICIO DOMÉSTICO: ¿REALIDAD O ESTEREOTIPO?}

El servicio doméstico es un tema sobre el que la historiografía muestra un creciente interés. Las primeras referencias hacia el mismo pueden encontrarse en trabajos como los de Hajnal, Laslett o Richard Wall', así como en la temprana y muy fructífera obra de Jean Hetch ${ }^{8}$. Las influencias europeas más relevantes de esta temática se filtraron en la historiografía española de la mano de autores como André Burguiere, Fauve-Chamoux o Rafaella Sarti, entre otros, encontrando acomodo en numerosos grupos de estudios ibéricos ${ }^{9}$. No hay que olvidar tampoco la aproximación al servicio doméstico femenino desde el punto de vista de la sexualidad realizado, entre otros, por Jean Louis Flandrin, Georges Vigarello y Laura Gowing ${ }^{10}$. La historiografía española sobre esta cuestión ha experimentado una auténtica revolución en los últimos años, al final de cuya estela debe situarse la presente investigación ${ }^{11}$.

El largo camino hacia el matrimonio constaba de una serie de ritos y acercamientos que no siempre se cumplían, dando lugar a situaciones consideradas anormales y, por lo tanto, peligrosas para el orden social: burlas, violaciones, marginación, ilegitimidad, etc. La extensa literatura referente a estas transgresiones, moralizante o no, nos indica que estos comportamientos, aunque indeseados, no eran desconocidos ni tabúes ${ }^{12}$. Tampoco puede hablarse

7 HAJNAL, 1983: 79-90. LASLETT, 1977. WAL RICHARD, 1978: 181-202.

8 HECHT, 1956.

9 FAUVE-CHAMOUX y FIALOVÁ, 1997: 57-73 y 125-163. MAZA, 1984.

10 VIGARELLO, 1998: 25-30. FLANDRIN, 1984. GOWING, 2003.

11 GARCÍA FERNÁNDEZ, 1994: 235-250. IRIGOYEN, 2010: 307-327. RAMOS y VERA, 1996.

12 FRANCO RUBIO, 2010: 53-104. PÉREZ TEIJÓN, 1990. 
de una regla general, estos procesos no siempre seguían directrices estables o predecibles, pues sus distintas realidades podían provocar rupturas o alteraciones en la norma.

La creciente actividad legislativa y judicial sobre matrimonios en el siglo XVIII permitió vislumbrar de manera más explícita la conflictividad social vinculada a las relaciones de pareja, acrecentando aún más el interés por controlarlas ${ }^{13}$. Entre los motivos de este proceder, los expertos han apuntado desde un auge del individualismo a la mayor valoración de la privacidad y a los conflictos de poder empleados para supervisar y modelar a la sociedad. A estos factores deben sumarse otros entre los que figurarán los crematísticos, no olvidemos que a fin de cuentas el matrimonio también era un negocio. En un contexto en el que el matrimonio requería de un fundamento económico inicial para funcionar de manera autónoma, la necesidad de mayores recursos obligó a muchas mujeres a emplearse fuera del hogar durante largo tiempo, contraviniendo la imagen idílica que se tenía del trabajo femenino.

Con anterioridad al siglo XVIII la figura de la criada no era en absoluto desconocida, perdiéndose su origen en la noche de los tiempos. A falta de una mayor amplitud de las fuentes sobre las actividades cotidianas, la mayor parte de los estudios sobre trabajo femenino han reconocido el del servicio doméstico como el empleo más usual desempeñado por la mujer fuera de su hogar ${ }^{14}$, aunque no el único obviamente. Es más, en numerosas ocasiones, este trabajo en el servicio doméstico parece guardar correspondencia con un periodo vital muy concreto ${ }^{15}$. Las jóvenes que componían el grueso del servicio doméstico femenino en el siglo XVIII solían responder a los apelativos de «criada», «sirvienta» y en determinadas circunstancias «casera». El perfil de estas mujeres era, generalmente, el de jóvenes solteras que buscaban ganarse la vida y forjarse una pequeña reserva o dote que en numerosas ocasiones resultaba imprescindible para contraer matrimonio. Esto implicaba que, las más de las veces, cuando entraban a servir estas muchachas eran muy jóvenes y no estaban comprometidas con nadie de manera definitiva. Una sirvienta, en principio, era en la mayoría de los casos y en origen una «doncella», definición semántica que trascendió hasta convertirse en el apelativo común de las criadas, a pesar de que también fuesen comunes las empleadas más maduras e incluso casadas.

El criado o la criada traían habitualmente consigo una serie de obligaciones muy similares a las de los aprendices gremiales los cuales, por efecto de la convivencia llegaban prácticamente a mimetizarse con los criados domésti-

13 El porcentaje de procesos iniciados en este tribunal a lo largo del siglo XVIII supone exactamente un $63,40 \%$ del total de los pleitos procesados en los tribunales eclesiásticos del tribunal diocesano de Huesca.

14 HAJNAL, 1983: 79-90, LASLETT, 1977, REY CASTELAO, 2005: 263- 269.

15 MARTÍN SORIANO, 1997: 197-209. 
cos, un detalle que puede llegar a confundir al investigador si no toma las oportunas precauciones. La compleja situación por la que podían llegar a pasar estas «doncellas» - acotada para muchas de ellas por la necesidad de contraer matrimonio y, al tiempo, de mantener su pureza - nos brinda una excelente oportunidad para analizar el papel de la mujer como sujeto activo en las relaciones de pareja del siglo XVIII. Lejos de su hogar y de su círculo de confianza, muchas de las criadas que hemos recogido lograban desplegar de manera autónoma los recursos, legales o morales, con los que podían defender sus intereses en las relaciones de pareja.

Descendiendo a un nivel analítico intermedio, hemos llevado a cabo esta investigación enfocándonos en el Valle medio del Ebro centrándonos en Aragón. Este territorio comprendido entre los Pirineos hasta más allá del Ebro, alcanzando las cuencas del Tajo y el Turia, nos permite contar con una muestra representativa de los diversos modelos familiares. De todos los pleitos por delincuencia sexual prematrimonial trabajados, en un $17,5 \%$ de los mismos el conflicto tenía como aspecto central la condición servil de la afectada $^{16}$.

Buscarse la vida como criada era un rasgo característico de las jóvenes con pocas posibilidades económicas, aunque no exclusivo de estas. Los datos arrojados por los pleitos estudiados muestran que en el $70 \%$ de los casos totales la pleiteante era una mujer ajena a la localidad donde está sirviendo como criada. Lamentablemente los pleitos no suelen hacer referencia a la población de origen, pero dada la rara intervención de sus familias en este tipo de pleitos nos hacen pensar que estas jóvenes - habitualmente de entre 20 y 25 años- estaban solas.

Aunque en algunos de estos pleitos encontramos directamente acusaciones de violación, lo más común eran casos que relataban un cortejo al uso que, por una u otra razón, fracasó antes de llegar al altar. Este era un fenómeno habitual, el camino al matrimonio comprendía un largo cortejo con una serie de ritos que permitían el progresivo acercamiento de la pareja sin que se precipitaran demasiado ${ }^{17}$. Así pues, entrar a trabajar en el servicio doméstico implicaba habitualmente la salida de los jóvenes de sus casas y un fácil acercamiento a cierta libertad sin supervisión ${ }^{18}$.

16 Estos pleitos corresponden principalmente a demandas por promesa matrimonial incumplida, estupro o violaciones. Las fuentes utilizadas pueden localizarse en los siguientes archivos: Archivos Diocesanos de Zaragoza, Huesca, Pamplona, Barbastro y Teruel, Archivo Provincial de Zaragoza, Archivo del Reino de Navarra.

17 Este punto puede encontrarse más desarrollado en: BALDELLOU, 2013: 75-110.

18 Véanse estudios como: SEGURA URRA, 2002: 147-166. USUNÁRIZ GARAYOA, 2010: $375-394$. 
Del mismo modo que las dependencias de estas criadas podían estar muy lejos de entrar dentro de las recomendaciones de los moralistas sobre los espacios de habitación propios de una doncella, lo mismo se podía decir de sus quehaceres que solían incluir tareas fuera del hogar, en lugares solitarios, tras la puesta de sol todo ello a la vez. Una situación que prácticamente eliminaba todas las barreras de recato que se recomendaba desplegar a una doncella.

La percepción de los problemas sociales relacionados con el servicio doméstico quedó reflejada en numerosos documentos, aunque no siempre de un modo objetivo. Las fuentes filosóficas e incluso las médicas de la época retrataban a la mujer como una figura lasciva y provocadora que, como Eva, hacía caer a los hombres en el pecado. No puede dudarse que, en algunos casos, los hombres pudieran ser provocados por algunas mujeres; sin embargo los tratadistas parecían olvidar - hasta muy avanzado el siglo XVIII-que, en la mayoría de las ocasiones, ellas podían resultar atractivas sin pretenderlo $\mathrm{o}$, aun pretendiéndolo, sin intención de provocar situaciones de fuerza o de pecado ${ }^{19}$.

Tal y como insisten varios autores ${ }^{20}$, el sacramento del matrimonio se trataba de la culminación de un proceso, habitualmente premeditado y largo, en el que todas las partes arriesgaban. Por esta misma razón, no se trataba de un cambio de estado social inmediato, existían una serie de actos y ritos que abrían el camino al mismo o incluso lo forzaban por encima de los pasos reglamentarios, si bien el azar $\mathrm{u}$ otros factores podían precipitar acontecimientos insospechados. De todos estos actos azarosos, las relaciones sexuales eran el primer desencadenante de un matrimonio no planificado. De acuerdo al derecho canónico ${ }^{21}$, la pareja que había tenido relaciones carnales se consideraba unida por verba de praesenti si antes se había dado palabra de matrimonio (verba de futuro).

La producción literaria moralizante a lo largo de toda la Edad Moderna hablaba de la necesidad de magnanimidad por parte del varón y del consentimiento que debía existir por la otra parte, pero también situaban al hombre en una posición de superioridad como dominador. La mujer, en cambio, tenía deberes tales como apoyar corregir, sugerir y en general actuar a modo de auxiliar en cuanto a la autoridad se refiere lo que nos conduce a un contundente principio ideológico: el hombre domina y la mujer transige. De este modo, partiendo de estas desiguales reglas de juego, analizaremos la situación más usual en las que se hallaba el servicio doméstico femenino.

19 LAQUEUR, 1999: 112-138.

20 CHARAGEAT, 2011: 12-30. CASEY, 2008: 15-35.

21 GARCÍA HERRERO, 2006: 225-227. 


\section{JUEGO DE POSICIONES: SITUACIONES Y FACTORES DE RIESGO}

Una joven del siglo XVIII era el centro de atención sobre el que se fijaban no pocas expectativas; más aún, cuanto más recatada, honorable, discreta, prudente, obediente o de mejor posición social era. Sin embargo, por el mero hecho de ser una mujer se la suponía — siempre desde un plano teórico- más débil que el hombre, al tiempo que docta en el uso de poderosas armas de seducción capaces de doblegar la voluntad masculina. Esto las convertía en culpables potenciales de cualquier encuentro sexual ilícito que se pudiese producir ${ }^{22}$. Si además la mujer en cuestión se trataba de una criada, la joven se convertía en un blanco ideal para el acosador al encontrarse lejos de la protección del hogar paterno y, a menudo, de su círculo de amistades ${ }^{23}$.

La literatura y los pleitos sugieren la existencia de un omnipresente peligro a caer en la deshonra, aunque también indican la relatividad del mismo. El matrimonio era el destino, casi inevitable, de toda mujer honrada del Antiguo Régimen - bien con Dios bien con un varón decente hecho, teóricamente, a imagen y semejanza-. Por ello las «familias de bien» tenían que ser conocedoras en sus casas de las tentaciones pecaminosas y de los modos de evitarlas. El amor por la familia, el recogimiento o la destreza en las tareas honrosas propias de su género eran las claves a través de las cuales una joven doncella demostraba que cumplía con las expectativas sociales requeridas. No obstante, como nos señalan los estudios sobre feminidad del siglo XVIII ${ }^{24}$, algunas de estas tareas estaban vedadas para las clases populares de similar manera que, salvando las diferencias, los ideales caballerescos lo estaban para el plebeyo. Lejos de muchos de aquellos valores encontramos la imagen popular de la criada: una mujer que pese a su juventud ha tenido que dejar su hogar familiar y, en ocasiones, su localidad para llevar a cabo diversos trabajos no siempre relacionados con el empleo doméstico ni con el mayor recato. Su supuesta proximidad, mayor o menor, al pecado hacía que el acoso sexual a las criadas incluyese muchos de los estereotipos negativos de unas mujeres propensas por naturaleza a relajar su castidad y su honradez que las convertía en un objetivo apetecible para la burla y la violación.

Entre los factores de riesgo, la separación de la muchacha de su círculo familiar era uno de los más determinantes. En la consecución de un buen casamiento participaban activamente las figuras paternas no solo como forjadores de estratégicas dotales -imprescindibles para poner en marcha un nuevo enlace familiar acorde a su posición-, sino también como celosos custodios de la honradez y de la virginidad de sus hijas. Luego, el fracaso social de es-

22 FOUCAULT, 2009: 30-64.

23 KILDAY, 2007.

24 MORANT y BOLUFER, 1996: 179-208. GARCÍA MARTÍNEZ, 2005. 
tas muchachas era concebido como la consecuencia de un proceso mal tutelado por sus progenitores. El análisis de los casos recopilados en los tribunales indica que las relaciones con sirvientas en las que de forma libre o coaccionada entregaban su virginidad eran más habituales cuando se trataba de mujeres que servían fuera de su localidad. En más del 70\% de los casos analizados, la criada agraviada era forastera. En cambio, habitualmente, el agresor solía ser oriundo de la localidad en la que se cometía el crimen. Consecuentemente, demostrar una falta contra el honor personal por parte de ellas podía resultar un asunto espinoso y harto complicado de constatar ante la posible ausencia de testigos de confianza.

FIGURA 1: Naturaleza de los litigantes en pleitos con criadas (1680-1820)

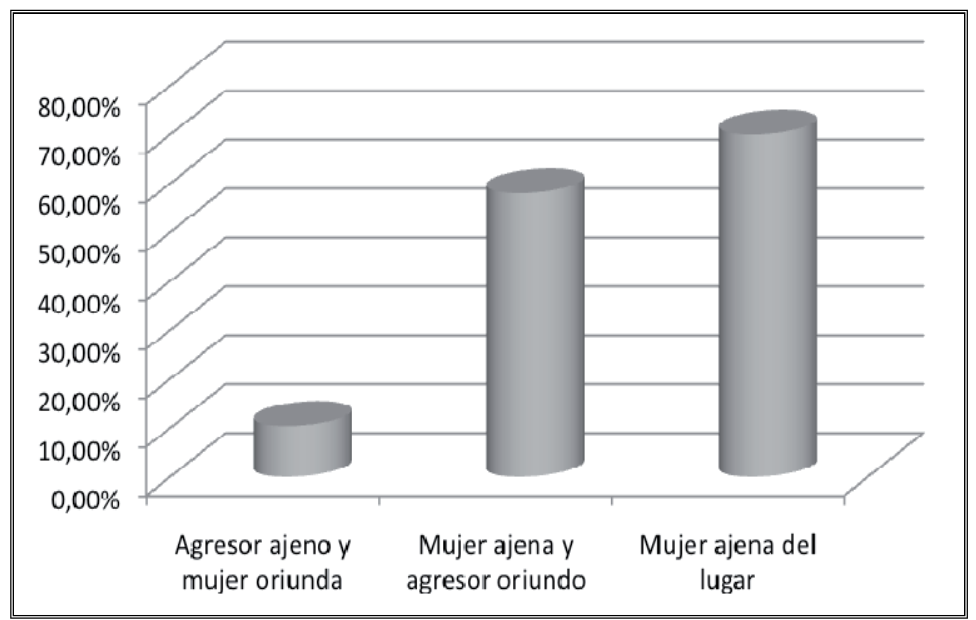

Fuente: Pleitos seguidos por los tribunales eclesiásticos de Zaragoza, Huesca y Barbastro.

La ausencia o la lejanía de los padres de ella facilitaban enormemente el cortejo y los excesos. El proceso de acercamiento a una muchacha solía iniciarse en espacios públicos donde la vigilancia quedaba relajada, tales como fuentes, lavaderos, mercados o eventos sociales concretos como las romerías, entre otros $^{25}$. Sin embargo, en un cortejo al uso éste solo era el primer paso que, dado el caso, los tribunales eclesiásticos entraban a valorar buscando su equivalencia como esponsales. Siguiendo el ritual de acercamiento, normalmente, el joven se daba a conocer a la familia de ella en un gesto «honesto y recatado» para hacerse con el beneplácito y el consentimiento público de los padres.

25 TESTÓN, 1985: 21-35. 
Contar con el consentimiento de ella y de su familia y mostrarlo en sociedad suponía disponer de testigos de dicha relación en caso de necesidad, tal y como se evidencia, por ejemplo, en el pleito que Isabel Villagrasa libró en 1774 contra su antiguo pretendiente, Francisco Pónsola. Este jóven, tras haber tenido trato carnal con ella, trató de casarse con otra mujer, algo que dejaba a Ysabel expuesta a la pública humillación. En el proceso, Villagrasa aportó numerosos testigos de diferentes condiciones sociales que ratificaron haber visto al novio «entrar en casa» de la denunciante. Sirva como ejemplo el testimonio de Magdalena Ferrer, «viuda honrada de la villa de Bujaraloz», quien declaró:

Que ha oído y ha visto a Ponsola frecuentar la casa de Villagrasa y asimismo el dicho Ponsola entró en su casa - de los padres de la Joven-y pidió casarse con una hija de la dicha y que antes de dar el visto bueno fue a casa del cura sabiendo que anteriormente habían concurrido allí dicha Ysabel y el dicho Pónsola para informarse si podía continuar en lo pedido por Pónsola.

En esta ocasión, la abundancia de testigos y el hecho de que pertenecieran a diferentes estratos sociales, incluyendo la confirmación dada por «viudas honradas» permitió a Isabel Villagrasa demostrar que el hombre que la había estuprado también la había cortejado y que entre ambos mediaban unos esponsales en firme. El resultado fue una sentencia favorable a la demanda de Villagrasa:

Fallamos por los autos y méritos de el proceso a que nos referimos que por lo que de ellos y dicho resulta debemos de condenar y condenamos al referido Francisco Pónsola a que dentro de el término de quince dias después de la notificación de esta nuestra sentencia contraiga matrimonio in facie eclesiae con la expresada Ysabel Villagrasa o la dote real o efectivamente en la cantidad de 200 ducados de vellón y también le condenamos en todas las costas de esta causa ${ }^{26}$.

En este caso, la honra de Ysabel Villagrasa quedó demostrada, pero el referido alejamiento de las criadas de su núcleo familiar y de la protección paterna implicaba que una forastera o casi desconocida tuviese pocas posibilidades de salir triunfante de este tipo de encuentros judiciales, donde los testimonios de los vecinos inmediatos eran a menudo las únicas pruebas de peso.

Otro lastre en la penosa situación en la que podían quedar las criadas solía estar condicionado por el espacio físico en el que desarrollaban su actividad. Como es sabido, el trabajo de las criadas consistía en una serie de labores que no tenían porqué quedar circunscritas al espacio físico de la morada. Su amplio cometido consistía en servir a la «casa» en el sentido más amplio, inclu-

26 AHPZ. Ligadura 4, Jactancia, E-F-G-H- num. 10. 
yendo dentro de esta a todo su patrimonio, así como todo aquello supuesto por el imaginario social y no sólo al espacio físico de cohabitación familiar ${ }^{27}$. De tal modo, aunque los contratos de las criadas solían hablar de servicio doméstico, no era raro que éstas realizaran tareas agropecuarias o artesanales dentro de los dominios de sus amos. La documentación procesal habla a menudo de sirvientas galanteadas o acosadas por mozos de la localidad, u otros sirvientes en espacios abiertos; si bien los espacios más habituales de seducción y de coacción para obtener favores sexuales de una mujer solían ser el hogar o espacios privados en los que ellas se hallaban solas. Fauve-Chamoux sugiere que los espacios abiertos y el tipo de trabajos pluripersonales allí realizados, junto con la coincidencia nuevamente en lugares de habitación, facilitaba el contacto entre criadas y jóvenes varones (criados, jornaleros o aprendices), cuyo estatus social llegaba a confundirse con el de este servicio doméstico ${ }^{28}$.

La separación de la joven del hogar familiar permitía mantener alejada la tutela paterna e incluso, a los ojos encendidos de algunos varones, la ocasión era interpretada como una incitación al sexo, saltándose el protocolo establecido para obtener una relación seria y de futuro:

Aprovechó que esta estaba en la noche en la hera por orden de sus amos para ir a por un cántaro de vino que este fue, comenzó a tocarla y a proponerle trato y matrimonio. Esta se negó, pero aprovechó la noche siguiente en la que el amo estaba fuera de casa, en dicha hera, para colarse en la alcoba donde ella dormía y proponer de nuevo, (...) lo logró y a partir de ahí volvió tres noches más ${ }^{29}$.

Como se aprecia, el acusado, Domingo Cerezuela, abordó a la mujer sin llevar a cabo ritual formal alguno. Más adelante retomaremos el significado de la proposición de matrimonio que siempre declaran las mujeres afectadas, pero en este momento interesa destacar el proceder del acusado: su intento por mantener relaciones con aquella a la que abordó al raso y en solitario. Así como que aún habiendo sido rechazado insistió hasta ser aceptado.

Saltarse el ritual de esponsales y permitir una aproximación rápida a estos pretendientes era poco recomendable, a pesar de que se daba con cierta frecuencia. Mostrar reservas era una de las pocas armas con las que contaba la mujer y eso tampoco era ninguna garantía. Las posibilidades de las criadas

27 PUJADAS y COMAS DE ARGEMIR, 1991: 131-150.

28 Fauve-Chamoux sugirió que el contacto entre ambos sexos dentro de los hogares era habitual y que en el siglo XVIII a esto tuvo que sumarse la explosión demográfica que superpobló muchos núcleos de población y condujo a situaciones confusas donde los límites de los oficios se volvieron más borrosos. FAUVE-CHAMOUX, ANTOINETTE, 1998: 112-129.

29 María Ardanuy contra Domingo Cerezuela, caso De Strupro et foedere matrimonii llevado por el Tribunal Diocesano de Barbastro en 1756, ADB, Lig. 61, 24 P-1010054. 
para mostrar recato podían quedar fácilmente en entredicho, ya que las labores cotidianas las obligaban a salir de casa para trabajar codo con codo con pretendientes o acosadores potenciales. Es más, las relaciones formales entre personas integrantes del hogar ${ }^{30}$ (incluyendo criadas, criados, aprendices, etc.) no solían ser mal vistas por el entorno más próximo, siempre y cuando no sobrepasaran las fronteras morales y sociales preestablecidas, tal y como refleja el siguiente documento datado en Huesca el año 1725:

Dice la expresada Micaela Aguilar que de aquí hace unos cinco meses que estaba sirviendo en la casa de Sebastián Marcem, el, que también era sirviente allí, en la casa del lugar de Marluenga, la solicitó una y muchas veces que se dexase conocer carnalmente la dicha Aguilar. Primero en la casa y luego otra vez en una heredad donde el amo los había mandado a acarrear haces. Y tantas fueron las palabras y los torpes intentos del dicho Marcem que este se aprovechó de la palabra dada en la heredad ${ }^{31}$.

En otras situaciones, el hombre aprovechaba la cohabitación de ambos bajo el mismo techo para acceder al trato carnal, no necesariamente por mutuo acuerdo y siempre temerosos de ser sorprendidos por el amo. La mujer no siempre denunciaba ser acosada ante el temor a la reacción de un amo al que debía convencer de su inocencia exclusivamente con palabras. Al llegar a los tribunales, si daba lugar, las sentencias solían ser favorables para ellas en caso de que lograsen convencer a la autoridad de haber intermediado palabras o promesas de matrimonio:

- La declarante- (...) hace constar y es notorio que Jacobo de Broto fue contratado por la casa de ella para recoger olivas como jornalero y en ese momento comenzó a tratarla y festejarla baxo palabra de matrimonio pidiendo que se dexase conocer carnalmente (...) Ella trabajaba como sirvienta en la casa y a menudo tenía que levantarse por la noche para ayudar a su amo que era anciano, él aprovechó una de estas visitas nocturnas para persuadirla a tener relaciones con él, cosa en lo que ella consintió tras recibir palabra de matrimonio ${ }^{32}$.

No debe de olvidarse tampoco que la palabra de matrimonio podía estar viciada, bien por ser una mentira destinada a grajearse los favores sexuales de las criadas, bien por ser una invención de ellas para «solucionar» con el matrimonio una posible situación irregular con resultados visibles a los nueve meses.

La inviolabilidad del hogar propio era una noción de seguridad recurrente en estos casos, pero el hecho de que el «household» fuera abierto las exponía

30 FOYSTER, 1999: 3.

31 ADH, 3-1 495/10.

32 Isabel Galmo contra Jacobo de Broto, 1751, ADB, lig 58, 30 P1010030. 
constantemente a hipotéticas transgresiones, facilitando que este tipo de encuentros tuviesen lugar. Estar dentro del mismo hogar que la mujer objeto de deseo era una ventaja física y psicológica para el agresor. No obstante, las ocasiones incitaban a los peligros o a pecados, pero de ninguna manera eran algo definitivo sino que quedaban abiertas a interpretación. Del mismo modo que la «entrada en casa» era un paso definitivo de la relación formal, este ritual de esponsales tenía su reflejo perverso en las coacciones y violaciones en las que determinado tipo de criminales entraban a hurtadillas dentro de las habitaciones donde yacían la criadas — desde pajares o cuadras hasta alcobas bien cerradas - con la pretensión de tener trato carnal.

La facilidad con la que algunos pretendientes podían acceder a estos espacios hay que buscarla, entre otras causas puntuales, en el propio rito de esponsales en el que se apoyaban. Si la entrada en casa es uno de los puntos de inflexión de una relación, el acceso al matrimonio en cualquiera de sus estadios implicaba para una pareja un cambio social al ganar, teóricamente, en autonomía y garantizar determinado derecho de coyunda. Este proceso de esponsales perduró fuera de la ley escrita e incluso fue defendido por los tribunales eclesiásticos, en buena medida, gracias al carácter indisoluble del matrimonio católico $^{33}$. La imposibilidad de romper el vínculo que unía a la pareja sin provocar un trauma social implicaba la necesidad de asegurar que la convivencia entre la pareja y los demás miembros de la familia fuera óptima o, al menos, tolerable.

Hay autores que incluyen las relaciones sexuales prematrimoniales en la categoría de «aproximación lícita» ${ }^{34}$, al entender que si el objetivo de la nueva pareja era la procreación era lógico que ese conocimiento previo alcanzase a las carnes como convencimiento de la idoneidad de las partes para contraer matrimonio. Además, el derecho canónico consideraba desde la Edad Media que dar palabra de matrimonio de futuro se convertía en matrimonio de facto o de praesenti si era seguido de cópula carnal. Para los tribunales diocesanos existía un estrecho vínculo entre el matrimonio y las relaciones sexuales, y aunque intentaban evitar que el derecho consuetudinario hiciera al segundo un sustitutivo del primero, dicha cópula era a menudo la ratificación definitiva de una promesa de matrimonio.

La idea caló en la conciencia popular, a lo largo de la Edad Moderna, quedando acreditadas diferentes prácticas rituales mediante las que el varón reclama, de una manera u otra, su derecho sobre la doncella y viceversa. Este modus operandi no solía tener mayores consecuencias siempre y cuando el proceso de esponsales culminase en matrimonio. En todo occidente parecían

33 COSTA, 2007: 189-210.

34 LEVENE, NUTT, y WILLIAMS, Illegitimacy in Britain, 1700-1920, New York, Palgrave Macmillan, 2005: 11. 
haber existido dos puntos comunes: la existencia de relaciones carnales prematrimoniales si no lícitas sí consentidas y la entrada en casa de manera más o menos consensuada ${ }^{35}$.

Se trataba de unas costumbres cuya regulación no dependía de leyes escritas y que, por lo tanto, raramente dejaban huella. Sin embargo, la facilidad con la que los jóvenes amantes o acosadores entraban en los lugares de habitación de estas doncellas, ya fuesen criadas o no, nos lleva a pensar que esta actitud juvenil era en cierto modo aceptada. Algunos autores incluso han vinculado el acto de entrar en los dormitorios de las jóvenes doncellas con actos cuasi públicos, como un rito iniciático mediante el cuál un joven mozo demostraba su virilidad ${ }^{36}$. La entrada en el hogar de la criada era el mecanismo más habitual utilizado por los infractores para convencer a la mujer de sus intenciones honestas de contraer matrimonio, fueran ciertas o no. Lo que desde el punto de vista de nuestros días podría parecernos una agresión en toda regla, que podía serlo, dentro del contexto surgido mediante promesas hechas en la alcoba y en plena noche alcanzaban un grado de compromiso formal; pues por muy coercitiva que fuera la situación, todo estaba dentro de la representación social de los pasos a seguir hacia el matrimonio. Aunque hayamos hablado antes del oportunismo con el que algunos abordaban a las mujeres fuera del hogar, en muchos de los casos de estupro contra criadas las relaciones carnales ocurrían en el lugar donde la criada dormía, muy a menudo alcobas, o espacios como cuadras o pajares donde el acceso era más fácil.

Los diversos obispados intentaron poner freno a este tipo de prácticas. El problema de la «copula carnale pre matrimonii» era tratado en numerosas constituciones sinodales del siglo XVIII. Desafortunadamente muchas de ellas se han perdido pero, en aquellas que nos han llegado, aparece continuamente una intensa actividad por parte de las autoridades eclesiásticas para fomentar actividades doctrinales contra las arraigadas resistencias culturales y los comportamientos heterodoxos.

Una de ellas son las moniciones sobre «Sponsalia et matrimonio de futuro ${ }^{37}$, generalmente orientadas a exigir el cumplimiento escrupuloso del ritual. Sirva como muestra la siguiente practicada en 1716 :

Que los desposorios y velaciones - entiéndase encajamiento - se hagan en un mismo día y se declara en qué tiempo se han de hacer. (...) Porque somos informados que en algunas personas que quieren recibir el Santo Sacramento del Matrimonio, en menosprecio de las Bendiciones Nupciales y de la exhortación del santo Concilio de Trento se desposan y cohabitan mucho tiempo sin recibirlas, deseando

35 GOWING, 2003: 125-140.

36 FLANDRIN, 1977, INGRAM, 1984: 79-113.

$37 \mathrm{ADH}$, Constituciones Sinodales, 1716, 1743 y 1744. 1.4/6/1 2 y 3. 
proveer de remedio mandamos que de aquí adelante los curas de nuestro obispado procuren que sus feligreses se desposen y velen en un día siendo tiempo de recibir las bendiciones nupciales ${ }^{38}$.

Las críticas a las bendiciones nupciales y sobre todo a la cohabitación son continuas. Las explicaciones que de ellas dan quienes las redactaron reproducen la existencia de infracciones como las de entrada en las casas ajenas, dando a entender que se trataban de visitas cuanto menos toleradas por los padres o los amos.

La entrada en el hogar formaba parte de la representación social del matrimonio como creación de un nuevo núcleo social básico, surgido a partir de la unión de dos esquejes provenientes de sendas familias. Se esperaba que el varón, como parte activa, tomase de la familia escogida la componente que necesitaba para formar la suya propia, es decir a la mujer. Esto supone que además del ritual del acceso a casa, existía una noción de rapto, secuestro o extracción de la mujer legítima. Evidentemente el secuestro tal y como lo entendemos hoy en día no estaba bien contemplado, pero sí que eran habituales las demostraciones de fuerza por parte del hombre para demostrar su virilidad y su capacidad de regir una familia. De esta forma, y pese a los intentos por parte de la iglesia de eliminar este proceder, el ritual del secuestro llegaba a organizarse, en ocasiones, incluso con la aquiescencia de los padres y de manera pública. Véase, por ejemplo, el contenido de la siguiente carta de Joseph Sánchez dirigida no a la mujer a la que pretende, sino a su futuro suegro:

Señor Diego Pérez, mi dueño y señor de Gerónima, mi querida, hija de usted es tanto lo que me roba el cariño que la deseo para mujer propia motivándome a esto su buena crianza, lo buena christiana, temerosa de Dios, honesta y persona que es y sobre todo el deberle tan cumplida asistencia como me hizo cuando pase las viruelas, cuya fineza tengo tan presente que no encuentro satisfacción mayor ni otra que casarme con ella que es todo lo que puedo hacer; y así de merecerla de usted la lleve a su casa. Y esto es, pareciéndole a usted bien que conmigo case en donde tendría usted, hasta que yo avise que no tardaré y esto en el mayor silencio como que tal cosa no ay sacándola de aquí con algún disfraz o diciendo que su madre esta mala ${ }^{39}$.

Este testimonio redundaba en la necesidad de obtener una aprobación pública en el proceso de formación de un nuevo matrimonio y a su vez trataba de colocar a la mujer en una posición de pasividad coartando la teórica libertad de matrimonio que ofrecía el Decreto Tametsi (de 1563 y en vigor hasta 1908) ${ }^{40}$.

38 ADH, Constituciones Sinodales, 1716, 1743 y 1744. 1.4/6/1 2 y 3.

39 ADZ, Jactancias, 1756, J, Lig. 6.

40 GAUDEMET, 1993, 311-380. 
Frente a ello la mujer se rebelaba no pocas veces, aun sabiendo que el panorama que se le abría era incierto.

La condición sociolaboral de las mujeres presentes en este tipo de procesos muestra variaciones significativas. Ciertamente, los pretendientes de aquellas mujeres amparadas en el seno familiar podían encontrar recursos para entrar en sus casas, ya fuese en visitas formales a los padres o burlándolos de mil maneras y acceder al dormitorio de la mujer. En aquellas casas donde las hijas están bajo la protección de la parentela, aunque solo fuese simbólica, los actos violentos eran más reducidos. Fuera de ese círculo resultaba más sencillo encontrar testimonios de acciones irregulares de «entradas en casas», con el agravante de estupro o no, acometidas gracias al engaño o la burla y con menor frecuencia, a un acto coercitivo o violento.

Muchos «burladores» optaban por evitar el largo protocolo social prometiendo matrimonio en la intimidad de la alcoba:

(...) es verdad que ha entrado varias veces de noche en las cassas de la madre de dicha Antonia Blasco en cuya compañía estaba esta y la dicha Antonia Blasco dixo y respondió que es verdad todo lo contenido, él estaba noticiado de que la dicha Blasco había tenido algunas torpezas con otros sujetos al tiempo que dicho Carlos Díez respondiente la empezó a festejar y conoció carnalmente pero siempre sin haberle dado palabra de casamiento. Ambos reconocen ser «iguales en naturaleza y por tales se tienen todo lo qual dixeron y respondieron y cada uno de ellos dixo y respondió ser cierto y verdad $»^{41}$.

Cuando el desfloramiento había sido «público y notorio» podía ser necesario ejercer cierta presión para forzar al burlador a contraer matrimonio; las posibilidades de acabar en el altar eran elevadas, especialmente si el caso lo llevaba el tribunal eclesiástico. Si el caso no daba giros inesperados, la presencia de la familia y de amistades resultaba decisiva:

La otra noche — cuando ella estaba embarazada, según otro documento- entró el declarante en casa de la dicha mujer y encontró a un hombre en la alcoba de la dicha preguntándole por sus relaciones y si había esposado con ella, por lo que salió corriendo, lamentablemente habían cerrado la puerta de la casa y se encontró atrapado y amenazado con una navaja por el hermano de la dicha y por su padre $(\ldots)^{42}$.

Este tipo de actos violentos, aunque muy explícitos, raramente se publicitaban al suponer un escándalo que en nada ayudaba a limpiar el honor de la

41 ADZ, 1779, Esponsales Lig. 2 ABCDEFG (2) 2.

42 ADZ, María Josepha Sánchez contra Antoni Salvador, Zaragoza, 1756, Jactancias, CAJA A-B-C-D-E, LIG 2. 
joven agraviada. Lo más habitual era que se recurriese a la presión social de los habitantes de la localidad quienes, al conocer a los litigantes, se consideraban con la autoridad necesaria para intentar corregir un comportamiento que afectaba a buena parte de la comunidad.

Los testimonios de personas civiles en los procesos judiciales se llevaban a cabo mediante preguntas prefijadas por el tribunal tras las declaraciones de los litigantes. En el elenco de preguntas siempre se encuentran referencias al comportamiento y moralidad de los pleiteantes. Una criada forastera era convertida más fácilmente en objeto de comentarios en la localidad, lo mismo que si su familia estaba ausente o no salía en defensa de su honra con contundencia.

En estos casos, eran las propias criadas las que tenían que abrirse camino lejos de sus familias y círculo social. Cuando sucedía, el papel de los amos a los que servían tomaba especial relevancia. Para Fray Luís de León, en La Perfecta Casada, una sirvienta debía ser educada como una hija por parte de sus amos, quienes debían velar por su comportamiento y su educación ${ }^{43}$. Según este principio, repetido en numerosos manuales de conducta ${ }^{44}$, la ausencia de la figura paterna debía ser suplida por el amo, quien debía cerciorarse de que la doncella siguiera el camino adecuado. Pues, según las creencias fisiológicas de la época, la mente femenina era inmadura y no siempre capaz de mantener el control.

De las indicaciones de los moralistas e intelectuales hechas en la línea de dotar de un tutor a las doncellas «solitarias», podría desprenderse que la situación de indefensión era mitigada por la figura de los amos. Sin embargo, tras analizar las fuentes notariales y procesales y comprobar la amplia casuística, creemos que no puede darse una respuesta única o general a la pregunta de si la figura de los amos, de algún modo, amortiguaba o prevenía las conductas desarrolladas o padecidas por sus pupilas. En unas ocasiones parece evidente que este control funcionaba, pero en otras el propio amo era el incitador a la perdición. Muchos casos quedan fuera de la percepción del investigador, sin embargo allí donde se puede ahondar, los resultados arrojados son suficientes para apartar la idea de que el amo ejercía el papel de padre con sus criadas, siendo poco usual el ejercicio activo de dicho tutelaje.

Con los padres fuera de juego, los amos podían ser para los jóvenes rondadores simples obstáculos, o incluso ser los amos los propios rondadores. La ambigüedad de los dueños de la casa de acogida se rompía cuando lo que se jugaba era su propia honra. No hay que olvidar que aunque las sirvientas no eran familia de sangre, lo que ocurriese en el interior de la casa afectaba directamente a la honra de la familia a la que representaba. Por lo tanto, dentro de la enorme diversidad casuística, los amos eran más o menos permisivos en

43 CAPEL MARTÍNES, 2005: 85-110.

44 GARCÍA MARTÍNEZ, ÁLVAREZ FAEDO y SIMÓN-SCHUHMACHER, 2005. 
cuanto a los contactos y amoríos de sus criadas, pero no podían tolerar que el escándalo salpicara ni afectara a su posición dentro de la comunidad.

Los amos no solían ser ajenos a aquellos casos en los que un extraño entraba amistosamente a visitar a su criada, salvo que los encuentros tuvieran lugar en espacios abiertos. No parece muy fácil que desconociera la existencia de una relación entre sus propios criados al cohabitar en su propio hogar, pero sí que hay testimonios que sugieren que se hacían los sordos hasta que alguien se pasaba de la raya. Tal fue el caso de la relación mantenida por Isabel Lacoma, criada, y Joseph Allué, aprendiz de notaría, al servicio del notario Joaquín Noballos. Al socaire de la convivencia, estos jóvenes aprovecharon para iniciar una relación que duró hasta que el amo los descubrió, circunstancia que precipitó unos acontecimientos no planificados que llevaron al aprendiz a salir corriendo y a la sirvienta a acusarle de estupro y abandono. En su testimonio, Joaquín Lorenzo Noballos, vecino de Huesca, de 53 años y ex-amo de ambos certificaba:

que ambos - litigantes - servían en las mismas casas, las suyas —es habitual utilizar el plural para hablar del patrimonio- - y que sabía de oídas que se habían dado palabra de casamiento y que en varias veces que se lo decía le respondía el declarante que con que la mantendría y que a ello le respondía que a ser maestro de niños. Sabe también de los festejos recíprocos que se daban y que una noche se despertó y se levantó de la cama al oír ruido y encontró (que) ella subía al cuarto de Allué, ella le dijo que lo hacía para hacerle la cama, a lo que el declarante respondió que a los criados no se les hacía la cama y mucho menos a horas como aquellas y viendo los hechos tan notorios se apresuró a despedirlos a ambos con poco más de un día de diferencia avisando antes a la madre de la susodicha para llevársela ${ }^{45}$.

Pese a la resuelta decisión del amo de los amantes por disolver el romance, en el proceso Joaquín Noballos fue cuestionado por acoger a una criada supuestamente problemática, a lo que el notario se defiende dando fe de la buena conducta de aquella:

Siempre consideró y considera a la dicha Ysabel Lacoma como mujer de bien, honrada y de buena vida, forma, reputación y costumbres; temerosa de Dios y de su conciencia ${ }^{46}$.

El testimonio refleja como el amo, a partir de un determinado momento, llegó a ser sabedor de los tratos habidos entre dos miembros de su casa y de cómo, sin embargo, no intervino contundentemente en el asunto hasta que la

45 ADH, 3-1 519/4, 1758.

46 ADH, 3-1 519/4, 1758. 
noticia se hizo pública, suscitando un escándalo que deshonraba a la casa. Sus posteriores declaraciones dan a entender que el noviazgo de sus dos subordinados entraba dentro de la normalidad, así que no hizo nada hasta que les descubrió en plena acción. Aún así, no sólo asistió como testigo, sino que tomó partido con claridad a favor del matrimonio entre ambos ante lo que, desde su punto de vista, era una cuestión de hechos consumados.

El cariño, la complicidad o, por lo menos, cierto grado de afinidad, y no sólo interés mutuo, solía impregnar las relaciones amo-criada. Sería el caso, entre otros muchos, de Lucas Malo «amo joven» de la criada Magdalena Ontiñano, la cual impulsó una jactancia por estupro contra Josef Garcés de Huesca por haberla engañado para tener trato carnal con él:

De esta forma el expresado Lucas Malo, amo joven de dicha casa llamada Del Tambor ${ }^{47}$, reprendió repetidas veces a dicha Ontiñano por el trato continuado que tenía con el dicho Garcés ${ }^{48}$ y del que tuvo noticia la misma noche que este entró en la casa.

En esta ocasión, el amo no expulsó a la criada, sino que trató de aconsejarle e incluso testificó a su favor en el pleito. El límite de lo consentido o el motivo desencadenante que empujaban a un amo a echar o no a sus criados por estas cuestiones son muy difusos y, muchas veces resulta imposible establecer una regla general al no quedar recogidos los sentimientos que mediaban entre ellos: simpatía, necesidad, compromisos sociales con la otra familia, prestigio social, etc. En este caso, la insistencia de que Lucas Malo era el «amo joven» y en cómo este nunca hizo nada más que reprenderlos pese a conocer todos los detalles, hace sospechar que la proximidad de edad entre este joven amo y su servicio implicó una cierta simpatía hacia sus actividades, cuando no colaboración.

Si el auxilio y la comprensión tuvieron lugar, la documentación nos muestra en mayor medida la otra cara de la moneda: la del amo tratando de abusar de sus criadas aprovechándose de una posición desigual. Visión que, por otro lado, cabe recordar que surge de una tipología documental muy precisa, la procesal, en la que posiblemente se silencian otros muchos casos, aquellos donde no hubo conflicto y donde el amo pudo obrar de un modo bien distinto. El acoso del amo recibido por la criada no era muy diferente del que podía padecer de otros miembros del hogar, salvo en el grado de autoridad y, en cualquier caso, mucho peor que cuando el delincuente vivía fuera. La subor-

47 Es habitual, incluso a día de hoy, que en ciertas localidades pirenaicas las casas comunes tengan nombre propio que no tiene porqué corresponderse con el apellido de sus moradores. ANDOLZ, 1993.

$48 \mathrm{ADH}, 3-1$ 26/5, 1770. 
dinación y el hecho de estar viviendo bajo su techo colocaban en manos del amo una ventaja estratégica insalvable de no rescindirse la relación laboral.

FIGURA 2. Distribución de los acusados de estupro o fuerzas a criadas de acuerdo a su vinculación con la casa y con la víctima $(1680-1820)^{49}$.

Estupro consumado fuera del hogar

Estupro con entrada del varón en el hogar de la criada

Estupro con trabajador cohabitante del hogar

Estupro con el amo o un familiar de este

Acusación de estupro sin determinar

Promesa matrimonial sin cópula

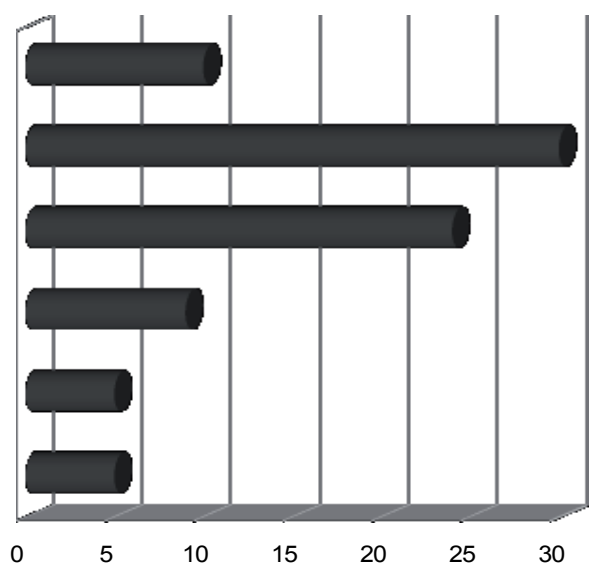

Fuente: Pleitos seguidos por los tribunales eclesiásticos de Zaragoza, Huesca y Barbastro.

Los casos recogidos por adulterio entre amos casados con criadas no son muy frecuentes. Su interpretación es múltiple - el alto nivel de coerción (tanto hacia la criada como hacia la esposa), la grave deshonra que suponía para toda la familia, el hecho de no ser denunciado en los tribunales solucionándolo de otro modo (incluso mediante la separación de hecho), etc., pero con certeza se dieron. El perfil del amo acosador encontrado es más bien el de un viudo - a menudo con una importante diferencia de edad con la criada - o el de un familiar cercano (un hijo, un hermano soltero o un sobrino; normalmente soltero). Las relaciones carnales entre amos y criados eran uno de los mayores escándalos que podían acontecer en una localidad; no solo se trataban a menudo de uniones que no podían terminar en matrimonio, también la desigualdad de edad o de posición social constituían fuertes agravantes. Cuando acaecían surgía una necesidad inmediata por identificar al culpable en todo su grado, pudiendo decantarse el favor de la comunidad tanto por la parte acusadora como por la acusada sin atenerse necesariamente a razones. La mujer, y más la pobre, siempre salía malparada. En los casos de las criadas, además,

49 Según los pleitos conservados en los Archivos Diocesanos de Zaragoza, Barbastro, Huesca y Teruel entre 1680-1820. 
podía quedar la sospecha de un plan urdido por ellas para lograr un matrimonio desigual o, simplemente, para acceder a la herencia o las propiedades del $\mathrm{amo}^{50}$.

La deshonra que suponía para el amo el conocimiento público de la existencia de trato carnal con una criada, conllevaba inequívocamente a la toma de soluciones drásticas. Despedir a la criada era una de las alternativas más evidentes, aunque esta opción no siempre servía de mucho si mediaba embarazo. Bien es cierto que a falta de testigos, el fruto de la relación era propenso a convertirse en un neonato ilegitimo o simplemente en un expósito. En cambio, si el tribunal eclesiástico consideraba probada la relación carnal, éste se decantaba por forzar el matrimonio de la joven con el estuprador en caso de concepción o en su lugar a una compensación económica y moral. Es por ello que en ocasiones se dieron intentos de ocultar el hecho. Esto ocurrió por ejemplo, con la familia de Blas Ayssa, un joven oscense que tras dejar embarazada a una sirvienta y ante las súplicas de ésta para que cumpliera con la palabra de matrimonio dada, el amo de la casa optó por una drástica solución:

y que él había sido el único causador que tomaron providencia para retirar a la nombrada Rosa Anzano de su casa y ponerla en lugar retirado y de su satisfacción en que pudiese salir de su parto y en efecto sin noticia de dicho Blas ni aún de los padres de la principal la trasladaron al lugar de Torralba y casa de Don Pedro Ayssa ${ }^{51}$.

Sacar de la comarca a una criada para parir discretamente al hijo de un clérigo o de un noble era una solución recurrente, además de matar al neonato o dejarlo expósito. Existieron de hecho ciertos casos célebres como el de don Juan de Palafox y Mendoza, hijo ilegítimo del Marqués de Ariza, el Pero Arnau de Peralta $u$ otros muchos Moisés que se enfrentaron a este mismo destino ${ }^{52}$.

La familia del ejemplo se vio obligada a revelar el paradero de la criada Rosa Anzano ante la presión ejercida por los padres de ésta y, posteriormente, de la autoridad civil. En otros casos, el acusado o su familia intentan demostrar que aunque hubo fornicación, no se dio palabra de matrimonio, pues no olvidemos que el recurso principal de la criada estuprada era alegar que se trataba de la culminación de unos esponsales.

Un matrimonio entre amo y criada forzado por las circunstancias suponía dar al traste con cualquier estrategia familiar pretendida, tal y como demuestra el hijo de un acusado ante la perspectiva de que la criada se convirtiese en la señora de su casa: «Que a su parecer la dicha Martina no llegó a contraer palabra de matrimonio con Juan Pasqual su padre pues esta obedeció lo que él

50 TAGGART, 1990.

51 ADH, 3-1 437/3, 1779.

52 ALFARO PÉREZ, 2013: 241-278. 
la mandaba» ${ }^{53}$. El hijo prefería claramente que su padre fuera acusado de fornicación antes que de estupro. De igual manera reaccionaban muchos de los acusados al declarar que ellos nunca habían dado palabra de matrimonio, tratando de plantear dudas sobre la honorabilidad de ellas, e incluso acusarlas de prostitución. La táctica consistía, de nuevo, en mostrarlas como un sujeto seductor y de perdición. Es más, una mujer que aceptaba a un hombre por dinero o sin palabra de matrimonio era, para ellos, la única culpable de lo que le pudiera ocurrir. La que, sin embargo, había recibido palabra de matrimonio - por muy precipitada que fuese- debía intentar demostrar que no había hecho nada imperdonable: un hombre la había propuesto matrimonio y ella lo había aceptado, su única falta había sido consumarlo antes de pasar por el altar. Ésta era la clave que explica la abundancia de pleitos por estupro y la escasez de acusaciones por violación: las mujeres insistían en la existencia de una promesa de matrimonio incumplida, aún cuando los testimonios describieran actos de fuerza:

«El dicho Villabona aprovechó un día en el que él estaba en la caballería, su amo no estaba en la casa y ella entró en dicha caballería, entonces él la forzó contra su voluntad recostándola con violencia sobre la madraquilla en la que él habitualmente dormía mientras este le decía que se callase y que no gritase que él le daba palabra de matrimonio ${ }^{54}$.

La demanda presentada por la víctima, Catalina Murillo, haciendo hincapié en que el acto se cometió «super foedere matrimonii», indica hasta qué punto temía la mujer expresar el haber sido violada. Sólo la denuncia y la promesa de matrimonio salvaguardaban su honor pasando a ser vistas como víctimas en caso de quedar embarazadas, pues estaba aceptado por la ciencia de la época que una mujer no quedaba embarazada si no había dado su consentimiento 55 . Las sentencias dictadas muestran el notable éxito de muchas mujeres en las demandas interpuestas en los tribunales eclesiásticos. Los pleitos que terminaban de manera favorable para las criadas no representan un número desdeñable. Muchas no sólo fueron exoneradas de toda culpa sino que, a menudo, se obligó al infractor a compensarlas de una u otra manera para restituirles su honor.

53 ADH, 3-1 361/10, 1745.

54 ADH, 3-1 100/2, 1748, Catalina Murillo contra Domingo Villabona.

55 LAQUEUR, 1999, 130-138. 
FIGURA 3. Sentencias resolutorias emitidas (1680-1820)

\begin{tabular}{|c|c|c|c|c|}
\hline \multirow{2}{*}{$\begin{array}{l}\text { Resolución de casos } \\
\text { Matrimonio }\end{array}$} & \multicolumn{2}{|c|}{ Muestra general } & \multicolumn{2}{|c|}{ Muestra específica de criadas } \\
\hline & 88 & $18,50 \%$ & 17 & $22,30 \%$ \\
\hline Pago de Dote & 24 & $5,00 \%$ & 9 & $10,40 \%$ \\
\hline Matrimonio y dote & 3 & $0,60 \%$ & 3 & $1,49 \%$ \\
\hline Aceptación matrimonio & 22 & $4,64 \%$ & 7 & $7,40 \%$ \\
\hline Fuga y persecución & 17 & $3,58 \%$ & 7 & $7,40 \%$ \\
\hline Absolición & 92 & $19,40 \%$ & 17 & $22,30 \%$ \\
\hline Separación voluntaria & 56 & $11,81 \%$ & 5 & $4,47 \%$ \\
\hline Sin resolución & 86 & $18,14 \%$ & 18 & $23,80 \%$ \\
\hline No presentado & 86 & $18,14 \%$ & 0 & $0,00 \%$ \\
\hline TOTALES & 474 & $99,81 \%$ & 83 & $99,56 \%$ \\
\hline
\end{tabular}

Fuente: Pleitos seguidos por los tribunales eclesiásticos de Zaragoza, Huesca y Barbastro.

Como se puede apreciar (Figura 3) fueron más las sentencias emitidas que reconocían la inocencia de la mujer, dándoles la razón, que las desestimadas. Entre los autos favorables para las criadas figuran: la obligación impuesta al infractor de cumplir su promesa de matrimonio, el pago de una dote compensatoria por los perjuicios causados y, en su caso, la manutención del hijo producto de la relación - o una combinación de ambas en los casos más graves- - La fuga del acusado también suponía la corroboración para el tribunal y para la sociedad de la inocencia de la mujer y de su buen proceder. Normalmente las litigantes buscaban en las sentencias estabilidad y reconocimiento de su inocencia. El matrimonio era el final feliz más deseado, pero no era la única alternativa. Una dote compensatoria equivalía al pago del tradicional «excrex» con el que un novio debía compensar a su pareja en pago por su virginidad; pero, sobre todo, suponía para ellas la recuperación de una honra puesta en entredicho. Por otra parte, las mujeres podían preferir no casarse con su violador, de manera que la dote era una salida que prevenía una posterior separación matrimonial y muchos disgustos. También se dieron casos en los que las mujeres acusaban en falso en busca de una dote, jugada arriesgada de la que se han constatado unos pocos ejemplos evidentes.

Las sentencias favorables para ellas se convertían en manifestaciones públicas con las que limpiar su nombre, la demostración irrefutable de su honra ante los ojos de una sociedad que solía verlas, por su naturaleza femenina, como culpables hasta que no se demostrara lo contrario. Los tribunales eclesiásticos tenían una alta valoración debido a la autoridad ejercida por la iglesia en temas de familia. Su efectividad en la persecución de delitos sexuales los convirtió, al menos desde época pos-tridentina, en la máxima institución moral a la que podía acudir una mujer de manera autónoma para defen- 
der sus católicos derechos, con independencia de su condición y de sus recursos económicos ${ }^{56}$.

A pesar del creciente número de pleitos por estupro durante el siglo XVIII, tratar de arreglar el problema con sigilo, sin mediar denuncia, buscando un arreglo que evitara el escándalo público, las costas y una sentencia no pactada, fue una constante. A estos casos nos referimos en la Figura 3 como Separación voluntaria, es decir: un arreglo en el que con un pago bajo cuerda o un matrimonio discreto las acusadoras accedían a retirar la demanda. Este interés por llevar el conflicto con discreción llevaba a disfrazar el acuerdo alcanzado mediante las correspondientes capitulaciones matrimoniales. Menos frecuentes son los textos en los que se habla de matrimonios forzados, abusos y burla. Los pleitos por jactancia, secuestro y esponsales en las diferentes diócesis eran una parte sustancial de su actividad legal, tanto en territorios de montaña como de llano, del interior como de la periferia, con uno u otro sistema cultural de herencias, económico o social, en el mundo rural y en el urbano, haciéndonos pensar que era un recurso bien considerado del que podía disponer toda mujer.

\section{CONCLuSIONES}

La escasez de obras literarias escritas por mujeres en el siglo XVIII supone una merma a la hora de evaluar cuál era la visión de ellas sobre este tipo de conflictos, si bien de sus declaraciones ante los tribunales eclesiásticos se desprenden algunos indicios o pautas repetidas. Desde el punto de vista de la retórica parecían tener muy claro que estaban pugnando en desventaja por tratarse de un mundo de hombres, viéndose obligadas - si querían salir airosas del lance - a adoptar el papel que ellos les atribuían: inferiores, humildes y recatadas. Baste recordar la imagen estereotipada - fisiológica e intelectual-que se tenía la mujer en la mentalidad de la época: un «casi hombre», un ser imperfecto que carecía de raciocinio suficiente, un ser que debía ser tutelado y supervisado constantemente por el varón. Imagen poco novedosa, por otro lado, como bien nos recuerdan las nociones ginecológicas medievales basadas en la rosa de los vientos y las células uterinas, unas acepciones por las que la mujer venía a ser poco menos que un varón sin terminar de hacer y que contrastaban con la imagen de la madre y de las advocaciones marianas donde a los atractivos femeninos - físicos y humanitarios - se sumaba el valor de la madurez, de la sabiduría.

Las distintas fuentes documentales resaltan la negligencia con la que algunos amos trataban a su servicio doméstico. De este comportamiento irregular

\footnotetext{
56 HOULBROOKE, 1797: 58.
} 
se hacía responsables a las criadas por ser mujeres, solteras y jóvenes con un alto grado de autonomía que además estaban bajo una supervisión considerada deficiente al no estar bien autorizadas o «enderezadas» por un padre o un pariente cercano. Las criadas eran concebidas como sujetos anómalos: desconocidas llegadas de una localidad más o menos lejana que estaban en una etapa en la que habían dejado de ser niñas, pero no eran aún esposas ni madres. La asumida superioridad masculina, combinada con la ausencia de una familia o de un círculo social afín las colocaba en una situación de máxima indefensión.

Por otra parte, los datos obtenidos de documentación procesal parecen demostrar que, una vez cometido el delito, estas mujeres tenían una posibilidad de resarcimiento recurriendo a los tribunales eclesiásticos. El alto porcentaje de sentencias favorables para ellas en los pleitos por estupro o esponsales indican que, efectivamente, disponían de una fuente de amparo legal y moral. Sin embargo, estos recursos estaban condicionados a una actuación muy concreta. Las criadas que recurrieron a estos tribunales no atacaban directamente la honra de su agresor. Una ofensiva explícita no era un atributo propio del ideal femenino y constituía una mala estrategia. En su lugar, se presentaban como víctimas asidas a virtudes como el recato y la pureza, atributos que habían sido sesgados de manera abrupta por la violencia o el engaño de los varones. Dicho alegato se basaba en una demostración de su inocencia con la que el tribunal las protegiera al tiempo que castigara al agresor.

Sobra explicar que las relaciones sexuales fueran o no prematrimoniales tenían un carácter atemporal, lo mismo que las tentaciones de la carne en sus dos versiones: la consentida y la forzada. En el Antiguo Régimen postridentino muchas de aquellas oportunidades encontraban su espacio en situaciones donde la mujer se hallaba sola, vulnerable o con grandes necesidades. Mujeres vulnerables conviviendo con jóvenes varones en edad de matrimonio: nunca fue bueno dejar la yesca cerca del fuego. El problema no radicaba tanto en que la yesca ardiera como en que se viera el humo: la deshonra de la criada y su familia, la vergüenza para la casa del amo, el lastre que suponía ese hijo bastardo nacido fuera del tronco y al que en ocasiones se abandonaba en un portal. A pesar de todo este riesgo, el deseo pesaba más que todas estas consideraciones pudiendo acabar el episodio de la peor manera. En cualquier caso, debe recordarse que las relaciones sexuales no tenían por qué estar basadas en el conflicto y que cuando lo hubo no siempre llegó a los tribunales. Las fuentes aquí presentadas son, en este sentido, tan sólo un fragmento concreto entresacado de una realidad mucho más amplia. Con todo, a pesar de estas limitaciones, gracias a ellas podemos conocer mejor algunos condicionantes que afectaron de forma trascendental a la conducta sexual - transgresora o de incierto finaldel servicio doméstico español en el siglo XVIII, mitificado o estereotipado por una literatura inspirada en situaciones muy reales. 


\section{BIBLIOGRAFÍA}

Adair, Richard, Courtship, Illegitimacy and Marriage in Early Modern England, Manchester, Manchester University Press, 1996.

Alfaro Pérez, Francisco José, «Ordenamiento foral y realidad socioeconómica de la mujer navarra (siglos XIV-XIX)», en Salas Auséns, José Antonio (Coord.), Logros en femenino. Mujer y Cambio Social en el Valle del Ebro, siglos XVI-XVIII, Zaragoza, Prensas Universitarias de Zaragoza, 2013; 241-278.

Andolz Canela, Rafael, El casamiento en Aragón, mitos y costumbres, Zaragoza, Mira Editores, 1993.

Baldellou Monclús, Daniel, «La posición de la mujer ante el matrimonio en las familias aragonesas del siglo XVIII», en Salas Auséns, José Antonio (Coord.), Logros en femenino. Mujer y Cambio Social en el Valle del Ebro, siglos XVI-XVIII, Zaragoza, Prensas Universitarias de Zaragoza, 2013; 75-110.

Beltrán Tarres, M., «De la relación con la madre: las mujeres como enculturadoras», en Cabré i Pairet, M., De dos en dos. Las prácticas de creación y recreación de la vida y la convivencia humana. Madrid, 2000; 55-79.

Bolufer Peruga Mónica, Mujeres e ilustración. La construcción de la feminidad en la España del siglo XVIII, Valencia, Valencia: Institució Alfons el Magnanim, 1998.

Cabrera Acosta, Miguel Ángel, «Historia y teoría de la sociedad: del giro culturalista al giro lingüístico», en Forcadell, Carlos y Peiró, Ignacio (Coord.), Lecturas de la Historia. Nueve reflexiones sobre Historia de la historiografia, Zaragoza, Institución Fernando el Católico, 2001; 255-272.

Capel Martínes, R. M, «Mujeres y educación en el Antiguo Régimen», Historia de la Educación: Revista Interuniversitaria, 26, 2007; 85-110.

Casey, James, Familia y sociedad en el Reino de Granada durante el Antiguo Régimen, Granada, Universidad de Granada, 2008; 15-35.

Chacón Jiménez, Francisco, «Familias, sociedad y sistemas sociales de los siglos XVI al XIX», en Bestard, Joan y Chacón, Francisco (coord.), Familias, historia de la sociedad española, Madrid, Cátedra, 2011, 325-392.

Charageat, Martine, «Cópula carnal. La preuve de mariage dans les procès à Saragosse au XV siècle», Mélanges de la Casa de Velazquez, 33/1, Casa de Velazquez, 2003; pp.47-63.

Chinchetru Pérez, Felisa, «El trabajo de las mujeres en el espacio económico: situación actual y perspectivas», en Ramos, María Dolores y Vera, María Teresa (eds.), Actas del Congreso Internacional «El trabajo y las mujeres pasado y presente», Málaga, Servicio de Publicaciones Universidad de Málaga, 1982; 25-44.

Costa, Marie, Conflictos matrimoniales y divorcio en Cataluña: 1775-1833, Tesis doctoral presentada no publicada, Institut Universitari d'Història Jaume Vicens Vives, 2007.

Dubert García, Isidro, «Domestic service and social modernization in Galicia, 17521920)», Continuity and Change, 14/2, 1999; 207-226. 
Fauve-Choamoux, Antoinette y Fialová, Ludmila (Ed), XIII Acta Demográphica, Le phénomène de la domesticité en Europe, XVI-XX siècles, Praga, Ceská Demografiká Spolecnost Sociologicky Ústav av cr, 1997.

Fauve-Chamoux, Antoinette, «Servants in preindustrial Europe, Gender difference», Historical Social Research, 23, 1998; 112-129.

García Bourrellier, Rocío, «Criados y familia en la España Moderna: aproximación desde Navarra (SS. XVI-XVII)», en Pérez Álvarez, María José y Martín García, Alfredo, Actas del XII Congreso de la Fundación de Historia Moderna, Madrid, Fundación Española de Historia Moderna, 2012; 1089-1100.

Flandrin, Jean Louis, La moral sexual en Occidente, Barcelona, Juan Granica Ediciones, 1984.

Foucault Michel, Historia de la Sexualidad, Tomo 1, Madrid, Biblioteca Nueva, 2009.

Foyster Elizabeth A., Manhood in Early Modern England. Honour, Sex and Marriage, London, Longman, 1999.

Franco Rubio, Gloria, «Mujeres transgresoras en el Quijote», en Segura Graíño, Cristina (coord.), La Querella de las Mujeres II 1405-1605: La Ciudad de las Damas y el Quijote, Madrid, Almudayna, 2011; 53-104.

García Fernández Máximo, «Resortes de poder de la mujer en el Antiguo Régimen: atribuciones económicas y familiares», Studia Histórica, Historia Moderna, 12, 1994; 235-250.

García González, Francisco (ed.), Historia de la familia en la península ibérica, balance regional y perspectivas: homenaje a Peter Laslett, Albacete, Universidad de Castilla la Mancha, Servicio de Publicaciones, 2008.

García Herrero, María del Carmen, Las mujeres en Zaragoza en el siglo XV, Tomo I, Zaragoza, Prensas Universitarias de Zaragoza y Sagardiana Editorial, 2006.

García Martínez, María Isabel, Álvarez Faedo, María José y Simón-Schuhmacher, Lioba, La educación de la mujer en el siglo XVIII en España e Inglaterra, Lewiston, The Edwin Mellen Press, 2005.

Gaudemet, Jean, El matrimonio en Occidente, Madrid, Taurus, 1993.

González del Castillo, Juan Ignacio, Obras Completas, Tomo II, Madrid, R.A.E., 1914.

Gowing, Laura, Common Bodies. Women, Touch and Power in Seventeenth-Century England, Yale, Yale University Press, 2003.

Hajanl John, «Two kinds of pre-industrial household formation system», En Wall, Richard, Robin, Jean y Laslett, Peter (eds.), Family Forms in the Historic Europe, Cambridge, Cambridge University Press, 1983; 79-90.

Hecht, Jean, The Domestic Servant Class in Eighteenth-Century England, London, Routledge \& Kegan Paul, 1956.

Houlbrooke, Ralph,Church Courts and the People during the English Reformation, 1520-1570, Oxford, Oxford University Press, 1979.

Ingram, Martin, «Ridings, rough music and the reform of popular culture in Early Modern England», Past and Present, 105, 1984; 79-113.

Irigoyen López, Antonio, «Aproximación al estudio del servicio doméstico del alto clero de Murcia durante el siglo XVIII», Obradoiro de Historia Moderna, 19, 2010; 307-327. 
Kilday, Anne Marie, Woman and violent crime in Enlightenment Scotland, Rochester, The Royal Historical Society, 2007.

Laslett, Peter, Family and illicit love in earlier generations, Cambridge, Cambridge University Press, 1977.

Laqueur, Thomas, Making sex, body and gender from the Greeks to Freud. Massachusetts: Harvard University Press, 1999.

Levene, Alysa, Nutt, Thomas y Williams, Samantha, Illegitimacy in Britain, 17001920, New York, Palgrave Macmillan, 2005.

Martín Soriano, Elena, «Aprendices y domésticos en el Alto Palancia: una estrategia familiar», en Chacón Jiménez Francisco y Ferrer i Alós, Llorenç (Coord.), Congreso Internacional Historia de la Familia: Nuevas perspectivas sobre la sociedad europea: Murcia, Seminario Familia y Élite de Poder en el Reino de Murcia. Siglos XV-XIX, Murcia, Universidad de Murcia, 1997; 197-209.

Maza Sarah, Servants and Masters in Eighteenth-Century France: The Uses of Loyalty, Princeton, Princeton University Press, 1984.

Morant Deusa, Isabel y Bolufer Peruga, Mónica, «Sobre la razón, la educación y el amor de las mujeres: mujeres y hombres en la España y en la Francia de las luces», Studia Histórica, Historia Moderna, 15, 1996; 179-208.

Pérez Teijón, Josefina, Literatura popular y burlesca del siglo XVIII, Salamanca, Universidad de Salamanca, 1990.

Pujadas Muñoz, Joan Josep y Comas de Argemir, Dolors «La Casa en el proceso de cambio del Pirineo aragonés», en Revista de Antropología Social, 1, 1991; 131150.

Ramiro Moya, Francisco, Mujer y trabajo en la Zaragoza del siglo XVIII, Prensas Universitarias de Zaragoza, Zaragoza, 2012.

Ramos, María Dolores y Vera, María Teresa (eds.), El trabajo de las mujeres. Pasado y presente, Actas del Congreso Internacional del Seminario de Estudios Interdisciplinares de la Mujer, Málaga, Universidad de Málaga, 1996.

Rey Castelao, Ofelia, «La sombra que brilla. Las mujeres en la España de la Edad Moderna», Ariadna, 18, 1998; 145-163.

Rey Castelao, Ofelia, «Mujeres en la economía campesina» en Morant, Isabel (dir.) y Ortega, M., Lavrin A. y Pérez Cantó P. (coords.) Historia de las mujeres en España y América Latina, Volumen II, El Mundo Moderno, Madrid, Cátedra, 2005; 263-286.

Salas Auséns, José Antonio (Coord.), Logros en femenino. Mujer y Cambio Social en el Valle del Ebro, siglos XVI-XVIII, Zaragoza, Prensas Universitarias de Zaragoza, 2013.

Sarasúa, Carmen, Criados, nodrizas y amos. El servicio doméstico en la formación del mercado de trabajo madrileño, 1758-1868, Madrid, Ed. Siglo XXI, 1994.

Segura Urra, F. «Víctimas y agresores: la mujer ante la justicia en Navarra durante la primera mitad del siglo XIV», en Erro, C. y Mugueta, I., Grupos sociales en la historia de Navarra. Relaciones y derechos. Vol. 1. Pamplona, (2002), 147-166.

Taggart, Ingrid, Enchanted Maidens. Gender Relations in Spanish Folktales of Courtship and Marriage, Princeton, Princeton University Press, 1990. 
Testón Núñez, Isabel, Amor, sexo y matrimonio en Extremadura, Badajoz, Universitas Editorial, 1985.

Usunáriz Garayoa, J. Ma (2010), «La violencia doméstica en la España de los siglos XVI y XVII: el ejemplo del reino de Navarra», en Escudero, J. M. y Roncero, V. (Coord.), La violencia en el mundo hispánico en el Siglo de Oro, 375-394.

Vigarello, Georges, Historia de la violación, siglos XVI-XX, Madrid, Cátedra, 1998.

Wall, Richard, «The Age of Leaving Home», Journal of Family History, 3, 1978; 181-202.

Recibido: 06/11/2013

Aceptado: 07/04/2014 